Article

\title{
Marketing to Youth in the Digital Age: The Promotion of Unhealthy Products and Health Promoting Behaviours on Social Media
}

\author{
Sally Dunlop ${ }^{1,2, *}$, Becky Freeman ${ }^{2,3}$ and Sandra C. Jones ${ }^{4}$ \\ ${ }^{1}$ Division of Cancer Screening and Prevention, Cancer Institute New South Wales, Eveleigh, NSW 2015, Australia; \\ E-Mail: sally.dunlop@cancerinstitute.org.au \\ ${ }^{2}$ School of Public Health, University of Sydney, Sydney, NSW 2006, Australia; E-Mail: becky.freeman@sydney.edu.au \\ ${ }^{3}$ Charles Perkins Centre, University of Sydney, Sydney, NSW 2006, Australia \\ ${ }^{4}$ Centre for Health and Social Research, Australian Catholic University, Melbourne, VIC 3000, Australia; \\ E-Mail: sandra.jones@acu.edu.au \\ * Corresponding author
}

Submitted: 7 December 2015 | Accepted: 11 March 2016 | Published: 16 June 2016

\begin{abstract}
The near-ubiquitous use of social media among adolescents and young adults creates opportunities for both corporate brands and health promotion agencies to target and engage with young audiences in unprecedented ways. Traditional media is known to have both a positive and negative influence on youth health behaviours, but the impact of social media is less well understood. This paper first summarises current evidence around adolescents' exposure to the promotion and marketing of unhealthy products such as energy dense and nutrient poor food and beverages, alcohol, and tobacco on social media sites such as Facebook, Twitter, Instagram and YouTube. We explore emerging evidence about the extent of exposure to marketing of these harmful products through social media platforms and potential impacts of exposure on adolescent health. Secondly, we present examples of health-promoting social media campaigns aimed at youth, with the purpose of describing innovative campaigns and highlighting lessons learned for creating effective social media interventions. Finally, we suggest implications for policy and practice, and identify knowledge gaps and opportunities for future research.
\end{abstract}

\section{Keywords}

advertising; alcohol; junk food; social marketing; social media; tobacco; youth

Issue

This article is part of the issue "Adolescents in the Digital Age: Effects on Health and Development", edited by Dan Romer (University of Pennsylvania, USA).

(C) 2016 by the authors; licensee Cogitatio (Lisbon, Portugal). This article is licensed under a Creative Commons Attribution 4.0 International License (CC BY).

\section{Introduction}

The digital age, in which youth are increasingly online, presents both challenges and opportunities for influencing their health and well-being. The potential to target and reach young people via online channels, both for companies selling unhealthy products and for institutions trying to positively influence health behaviours, is unparalleled.

The most recent media monitoring data from the Pew Research Centre shows that 92\% of 13-17-year- olds in the United States (US) report going online daily, with $56 \%$ doing so several times a day and $24 \%$ "almost constantly" (Pew Research Center, 2015). Among these 13-17-year-olds, 71\% use Facebook, 53\% use Instagram, 41\% use Snapchat, and 33\% use Twitter. In 2014, among 18-29-year-old US internet users, 87\% used Facebook, 53\% used Instagram, 37\% used Twitter, and 34\% used Pinterest (Duggan, Ellison, Lampe, Lenhart, \& Madden, 2015).

Importantly, the rise of social media has taken place concurrently with changes in the way people ac- 
cess the internet; the use of mobile devices which allow access "from anywhere at anytime" mean that people are exposed to marketing messages on social media near or at the point of purchase/decisionmaking. The Pew youth media study noted that $88 \%$ of teens have a mobile phone, with $73 \%$ owning or having access to a smartphone; over $90 \%$ access the Internet from their mobile device, and those who do so are online more frequently (Pew Research Center, 2015).

By far the most commonly used, and extensively researched, social networking platform is Facebook. In 2013, less than a decade after its launch, Facebook had 1.23 billion monthly users worldwide (Facebook, 2014). While the most comprehensive usage data comes from the US, we also know that in Australia Facebook had 12 million users in 2014 (Ross, 2014); and in the UK more than $40 \%$ of $6-14$-year-old and $90 \%$ of $15-24$-year-old internet users were accessing Facebook in 2011 (Winpenny, Marteau, \& Nolte, 2014).

Another social networking platform popular with youth is YouTube, an interactive video-sharing site where users can upload their own videos and receive feedback and comments. Youtube is the second most popular social networking site (Pew Research Center, 2014), with over one billion users and video content which reaches billions of views per day (YouTube, 2015). YouTube is particularly popular with adolescents (three-quarters of 12-15-year-olds in the UK watch YouTube [Ofcom, 2014]) and young adults (YouTube reaches more 18-34-year-olds in the US than any cable network [YouTube, 2015]).

In this paper, we first summarise current evidence around youth exposure to the promotion and marketing of three categories of unhealthy products-energy dense and nutrient poor food and beverages, alcohol and tobacco-on social media sites such as Facebook, Twitter, Instagram and YouTube. We then present examples of health-promoting social media campaigns aimed at youth, with the aim of highlighting innovative and effective components of such campaigns.

\section{Youth Exposure to Promotion and Marketing of Unhealthy Products on Social Media}

There is overwhelming evidence that children, adolescents and young adults are exposed to and influenced by marketing of unhealthy products in traditional media (Anderson, de Bruijn, Angus, Gordon, \& Hastings, 2009; Cairns, Angus, \& Hastings, 2009; National Cancer Institute, 2008). The Internet provides marketers with an array of new channels and tools for disseminating their messages. However, the advent of social media has fundamentally altered the marketing landscapemoving young audiences from passive recipients of advertising to active participants in the co-creation and dissemination of marketing messages. Unlike traditional forms of advertising that target potential customers with ads, companies that join in the "complex network of relations" of social media "befriend" their customers, which is a particularly appealing approach for companies wanting their consumers to express their personality through brand association (Freeman \& Chapman, 2010). In the following sections, we outline how youth are exposed to and interact with messages from companies selling unhealthy food and beverages, alcohol and tobacco on social media.

\subsection{Energy Dense and Nutrient Poor Food and Beverages}

Childhood and adolescent obesity is a global public health challenge. In the US for example, $34.5 \%$ of all 12-19-year-olds are considered overweight or obese and these young people are at high risk of going on to develop chronic health conditions in adulthood caused by their excess weight (Ogden, Carroll, Kit, \& Flegal, 2014). The promotion of energy dense and nutrient poor food and beverages on social media is well documented in marketing case studies of successful campaigns. From Oreo cookies (Our Social Times, 2013) to Burger King chicken sandwiches (Colenso BBDO, 2015) and bottles of Coke (Shively, 2014), social media platforms have proven an ideal avenue for brands to experiment with irreverent and highly sharable campaigns (see Figures 1 and 2 for examples of these campaigns). Social media platforms are proving to be an ideal medium for food and beverage companies to engage with young people. A US market research survey found that $63 \%$ of $13-32$-year-olds have posted a photo on social media of food or drinks they or someone else was consuming, and $57 \%$ have posted on social media about what they're eating (YPulse, 2015). The photo-sharing social media site, Instagram, with more than $40 \%$ of users aged $16-24$ (DMR, 2015), currently has over 71 million posts tagged as \#foodporn. Savvy food and beverage companies capitalise on this consumer-driven marketing.

In 2014, it was estimated that social media advertising by food and beverage brands across the 12 top international markets would reach US\$3.0 billion (Socintel360, 2014). In the US, the Federal Trade Commission reported that total youth-targeted (age 2-7) food marketing expenditures on new media, including corporate websites, advertising on third-party children's websites, marketing via mobile devices, and social media, increased by $\$ 45.9$ million from 2006 to 2009, totalling $\$ 122.5$ million (Powell, Harris, \& Fox, 2013). While a broader body of work has assessed the impact of this increase in web-based food and beverage marketing on children, only a small number of public health studies have assessed the content and types of marketing aimed at young people through social media platforms. 
Oreo with Arzola Genesis and 44 others.

20 September $2012 \cdot$ e

Our band 'o pirates never dunked. We walked th' plank. http://oreo.ly /dailytwist

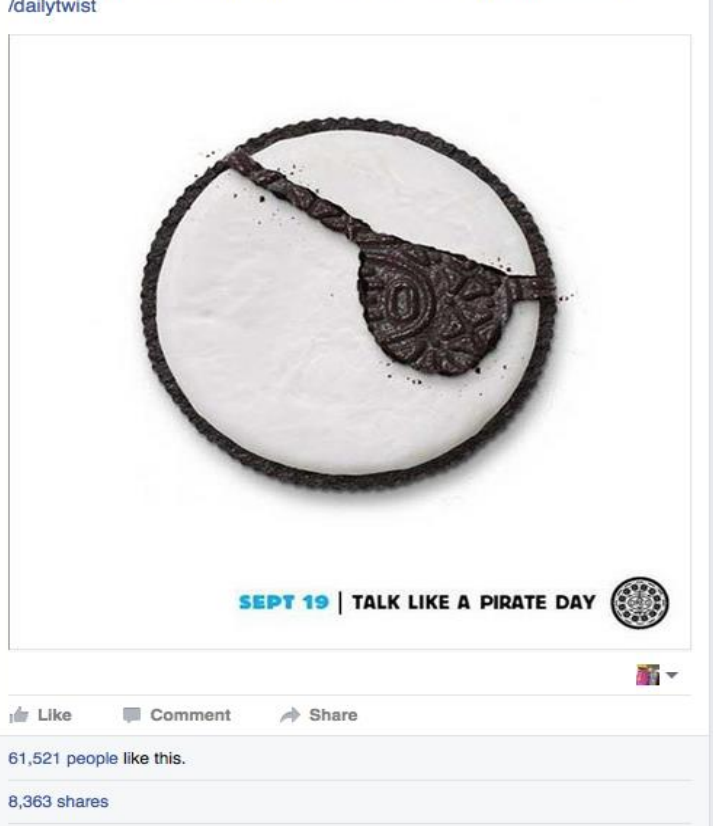

Figure 1. A typical post by the official Oreo cookie Facebook page. Source: https://www.facebook.com/oreo/timeline

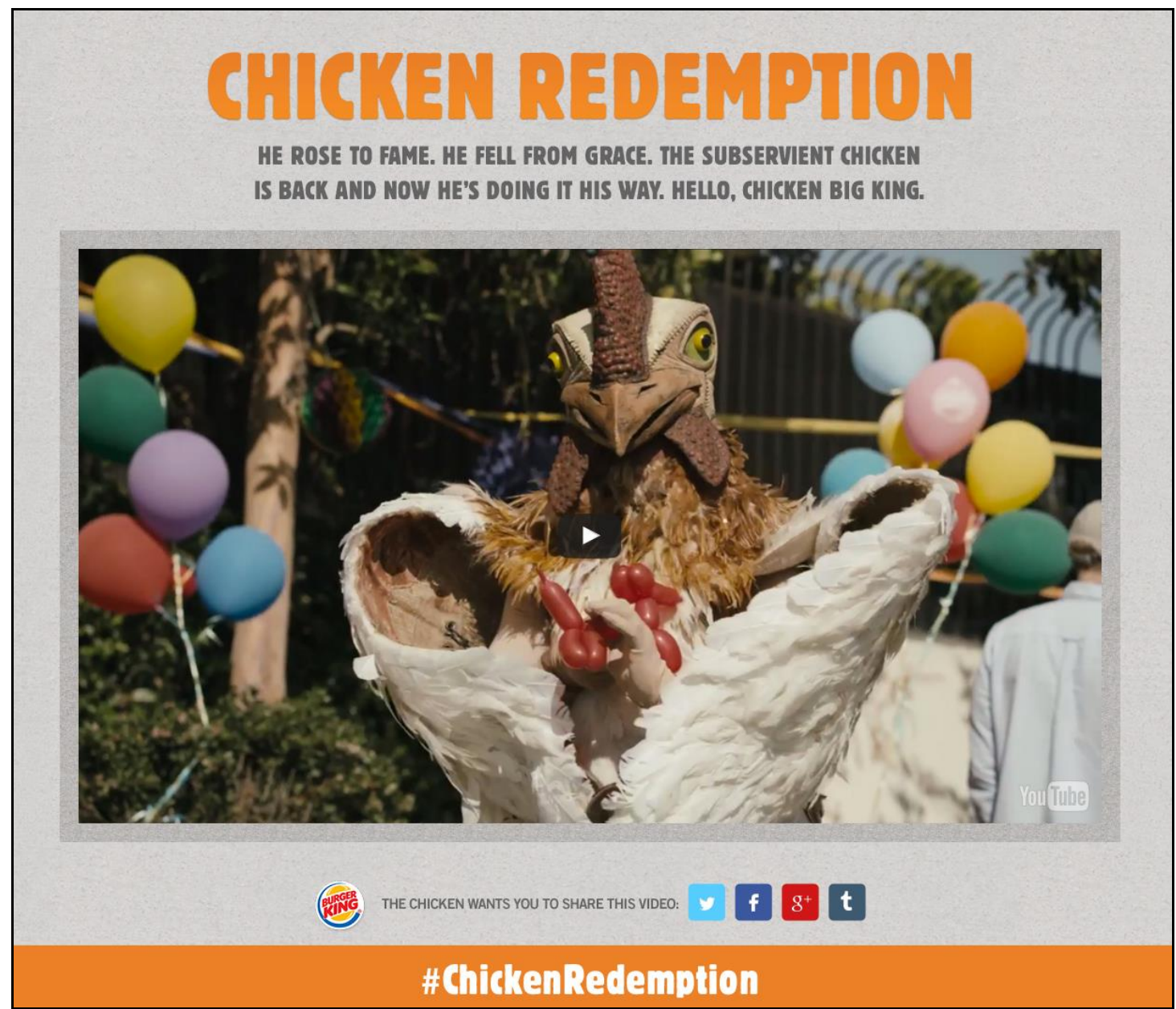

Figure 2. The successful subservient chicken campaign by Burger King. Source: http://www.subservientchicken.com 


\subsubsection{Techniques Employed by Food and Beverage Marketers on Social Media}

An Australian study that audited the digital media marketing tactics of three top selling food and beverage brands found that, of the 21 digital promotional platforms employed by the three brands, seven were located on the popular social media site, Facebook (BoelsenRobinson, Backholer, \& Peeters, 2015). The target audience for this digital marketing was deemed to be primarily adolescents aged 13-17 and children aged 12 and under. Common techniques used to engage children and adolescents with these unhealthy food and beverage brands included flash animation, music and games. A more extensive study of the 27 most popular food and beverage brand Facebook pages in Australia found that marketing features unique to social media, such as competitions based on user-generated content that increase consumer engagement, were used widely (Freeman et al., 2014). Twenty-three pages included strong evidence of increased interaction between brand owners and Facebook users, with the page administrators responding directly to user posts, liking and replying to comments made by users, or sharing user posts. Adolescent (1317-years-old) and young adult (18-24) Facebook users appeared most receptive to engaging with the marketing content. These users were found to willingly spread marketing messages on behalf of food and beverage corporations with seemingly little incentive required.

\subsubsection{Exposure to Food and Beverage Marketing on Social Media}

Measuring young people's actual exposure to food and beverage marketing on social media platforms and the effect this exposure has on their dietary choices is an urgent public health priority. Exposure to social media advertising has likely increased alongside the increased use of social media and increased spending on social media advertising. A comprehensive 2012 US monitoring study of 18 different popular chain fast-food restaurants found that online display advertising on Facebook alone totalled almost $\$ 6$ billion and represented $19 \%$ of all fast food display advertising (Harris et al., 2013). The individual social media pages of 17 of the 18 fast-food outlets assessed in the study had 1 million or more Facebook likes (compared with nine in 2010), and six had more than 10 million (Harris et al., 2013).

In light of unhealthy food and beverage brands heavily using social media advertising (Montgomery, Chester, Grier, \& Dorfman, 2012), public health professionals have called for interventions and polices targeted at protecting children (World Health Organisation, 2010), adolescents (Williams, 2013) and young adults (Freeman, Kelly, Vandevijvere, \& Baur, 2015). The predominantly voluntary nature of advertising codes meant to only limit young children's exposure to unhealthy food and beverage marketing has had a minimal impact on their actual exposure to advertising (BoelsenRobinson et al., 2015; Obesity Policy Coalition, 2011). Additionally, most voluntary codes do not encompass social media platforms as these are seen as primarily targeting adolescents and young adults who fall outside the voluntary codes (Boelsen-Robinson et al., 2015).

\subsection{Alcohol}

A common finding across countries is that 18-24-yearolds are the age group with the most problematic levels of alcohol consumption. For example, in the US, it has been estimated that over 13 million 18-24-year-olds drank five or more standard drinks in a single sitting at least monthly in 2013 (SAMHSA, 2013). In Australia in the same year, $46 \%$ of this age group reported drinking five or more standard drinks in a single sitting at least monthly, including $18 \%$ who reported drinking 11 or more (Australian Institute of Health and Welfare, 2014).

There is increasing evidence that alcohol initiation during childhood or adolescence is associated with more problematic drinking in adulthood; and that alcohol advertising is associated with drinking initiation (Anderson et al., 2009; Smith \& Foxcroft, 2009). Thus, one of the primary aims of regulatory restrictions on broadcasted alcohol marketing is to reduce youth exposure to alcohol marketing per se and/or to particular messages or appeals in alcohol advertising (Jones \& Gordon, 2013). However, it appears that such restrictions, which are typically in the form of industry self-regulation, are ineffective even in traditional media such as magazines and television (Hastings et al., 2010; Jones, Hall, \& Munro, 2008; Smith, Cukier, \& Jernigan, 2014). Social media provides alcohol marketers with new opportunities for avoiding even these restrictions and engaging with young people (Jernigan \& Rushman, 2014; Jones, Robinson, Barrie, Francis, \& Lee, 2015).

By far the most researched social networking platform for alcohol-related content is Facebook, with increasing evidence of an association between usergenerated alcohol-related posts on young people's Facebook profiles and (problem) drinking (Hebden, Lyons, Goodwin, \& McCreanor, 2015; Litt \& Stock, 2011; Moreno, Christakis, Egan, Brockman, \& Becker, 2012; Ridout, Campbell, \& Ellis, 2011). However, alcohol is a common topic of conversation across all forms of social media; for example, studies of Twitter traffic have identified that self-referent drinking-related tweets are common and peak on weekend nights, public holidays and special events (Ramezani, Terdal, Pepper, \& Anderson, 2014; West et al., 2012).

\subsubsection{The Rules (and Tools) for Alcohol Marketing on Social Media}


In the US, industry-specific codes govern alcohol marketing on digital media. The provisions include placement only where at least $71.6 \%$ of the audience is of the legal purchase age ${ }^{1}$ requiring age affirmation prior to engagement in direct interaction with a user, and ensuring forwardable content includes instructions not to forward to individuals below the legal purchase age (Beese, 2015). Other countries provide varying degrees of regulation or guidance on the placement of alcohol marketing online, including social media; ${ }^{2}$ and there have been calls for a global response to the regulation of online alcohol marketing (Casswell, 2012). In Australia, the industry code (ABAC Scheme, 2014) covers "digital communications (including in mobile and social media and user generated content)"; however, the Code focuses on content rather than placement. ABAC also provides marketers with best practice guidelines, which include age verification-but the document emphasises that "This advice is non-binding...it is intended as guidance to assist advertisers and agencies" (ABAC Scheme, 2014). Finland is one of few exceptions to this process of allowing industry bodies to drive the social media agenda, with a ban on alcohol advertising in social media imposed from the beginning of 2015 (European Centre for Monitoring Alcohol Marketing, 2014).

Facebook requires users to provide their date of birth when they establish a profile (although there is currently no process to verify the accuracy of this information). Alcohol brand pages, advertisements and posts are only made visible to those users whose profiles indicate that they are over the legal age in their country of residence. Twitter does not require age information to establish a profile but offers an agescreening tool for alcohol marketers, which activates a request for date of birth. The follow request is declined if the date entered indicates they are under the legal age in their country of residence. YouTube does not automatically control or block underage access but has a facility that enables brands to require date of birth entry information and/or to limit access to a channel to registered users. As at the time of writing, Instagram does not have an age verification process.

\subsubsection{The Extent and Nature of Alcohol Marketing on Social Media}

\section{A 2011 analysis of Facebook walls and Twitter timelines}

\footnotetext{
${ }^{1}$ Some countries, such as the US, have a legal "drinking age" (consumption of alcohol below this age is an offence) whereas others have a legal purchase age (purchase or public drinking below this age is an offence but drinking per se is not). For simplicity, in this paper the terms "underage" and "over the legal age" are used to indicate being below/above the legal drinking or purchase age (as applicable) in the country of data collection.

${ }^{2}$ A full review of these is beyond the scope of the current paper. Thus, these examples are given for illustrative purposes
}

of 12 UK alcohol brands found that all had a Facebook page (ranging from 1290 to $1,892,575$ likes) and six had a Twitter feed (from 2211 to 27,078 followers) (Nicholls, 2012). Across the month of analysis, there were 701 brand-authored posts; with frequent use of strategies such as real-world tie-ins, interactive games, competitions and time-specific suggestions to drink. A 2012 study of five alcohol brands, also in the UK, found Facebook likes ranged from 70,024 to 183,091; Twitter followers from 47 to 3984; YouTube subscribers from 14 to 11,561 and YouTube video views from 14,837 to 9,351,097 (Winpenny et al., 2014).

An analysis of the Australian Facebook pages of 11 alcohol brands found they had an average of 75,000 likes (range 8,326 to 176,633 ), the majority of whom stated their age as 18-24, and an average of 33.5 albums and 1,828 photos (Jones, Robinson, \& Barrie, 2013). Posts on the brand pages during the six-week study ranged from 4 to 23 by the brand and between 4 and 1,035 for followers. An earlier US study found 93 commercial Facebook pages with more than one million "friends" for top beer brands and 334 pages with more than three million for top spirit brands, with a vast array of applications and activities available through or promoted on these pages (Mart, Mergendoller, \& Simon, 2009). A search of drinkingrelated content on Twitter identified 11,966,381 English-language tweets in a one-month period in 2014; the most common keyword was "drunk" (5,336,372), followed by "beer" $(3,444,778)$ and "alcohol" $(1,565,258)$ (Cavazos-Rehg, Krauss, Sowles, \& Bierut, 2015). Analysis of a random sample of 5,000 of these tweets identified that $16 \%$ were commerciallygenerated marketing or promotion.

\subsubsection{The Accessibility and Impact of Alcohol Marketing on Social Media}

Researchers in the US explored the use of age restrictions on YouTube by creating fictitious profiles of users aged 14, 17 and 19 (Barry et al., 2015). All three (underage) profiles were able to subscribe to the YouTube channels for each of the 16 selected alcohol brands, and on average to view two-thirds of the brands' videos. The same researchers created fictitious Instagram user profiles aged 13, 15, 17, 19 and 21 (Barry, Olunfunto, Martin, \& Jackson, 2015). For thirty days, they followed the official Instagram pages of 22 alcohol brands. In addition to being able to follow the pages, they received-direct to their smartphones-an average of 373 advertisements during the month of the study; and comments and requests posted by the underage profiles were responded to directly by the brands' representatives. In a UK study, researchers established fictitious profiles on Facebook, Twitter and YouTube for a 14-year-old and a 24-year-old user (Winpenny et al., 2014). Only the 24-year-old could ac- 
cess the Facebook pages of five alcohol brands, but both could access all of the YouTube channels and three of the five Twitter accounts.

A survey of US college students (mean age 21.4 years) found that almost all (96\%) used social media (Hoffman, Pinkleton, Austin, \& Reyes-Velazquez, 2014). Multivariate analyses showed that participants' interaction with alcohol-marketing on social media, but not their social media use per se, predicted both alcohol consumption and problem drinking. Consistent with these findings, a survey of 283 Australian Facebook users aged 16-24 years found no association between alcohol consumption and general Facebook usage. However, while only $20 \%$ of the users had actively interacted with an alcohol brand on Facebook, there was a significant association between active interaction (liking, posting, commenting, or uploading/tagging) and both alcohol consumption and problematic drinking (Jones et al., 2015). An experimental study with US college students (mean age 20.6 years) found an association between attitudes toward alcohol-marketing status updates and drinking intentions (Alhabash, McALister, Quilliam, \& Richards, 2015). Those who reported stronger viral behavioural intentions (such as intending to like, share or comment on the posts) reported higher intentions to consume alcohol; and the strength of this relationship increased when the post had more likes or shares.

\subsection{Tobacco}

Despite declines in adolescent smoking in developed countries such as the US and Australia, smoking among young adults (18-24 years) continues to be relatively high $(16.7 \%$ in the US [Centers for Disease Control and Prevention, 2015]) and 23.2\% in Australia (Australian Institute of Health and Welfare, 2014), and smoking initiation continues to occur primarily in adolescence or early young adulthood (Australian Institute of Health and Welfare, 2014; Bernat, Klein, \& Forster, 2012). Given the depth of the evidence demonstrating the impact of tobacco promotion on tobacco use (National Cancer Institute, 2008), the WHO Framework Convention on Tobacco Control (FCTC) requires a comprehensive ban on tobacco advertising, promotion and sponsorship. The guidelines for Article 13 state that if only certain forms of advertising are prohibited, the tobacco industry inevitably shifts its expenditures to other areas of promotion, especially among young people (WHO Framework Convention on Tobacco Control, 2015). The continually evolving landscape of social media therefore offers a prime opportunity for tobacco companies when advertising in traditional media is prohibited.

Most social network sites have policies restricting the direct advertising of tobacco products. Facebook's advertising policies stipulate that ads may not promote or facilitate the sale or consumption of tobacco products (Facebook, 2015a), with advertisements and commercial content on Facebook fan pages also subject to these guidelines (Facebook, 2015b). Like Facebook, YouTube does not allow tobacco products to be advertised (Google, 2015), however the definition of advertising only applies to paid forms of promotion, such as advertisements embedded in videos or advertisements that appear for key word searches.

\subsubsection{The Extent and Nature of Tobacco Marketing on Social Media}

The most researched social media site in the tobacco control field is YouTube, with many studies describing the prevalence and type of tobacco-related imagery on the site, ranging from product reviews to smoking fetish imagery (Cranwell et al., 2015; Elkin, Thomson, \& Wilson, 2010; Forsyth \& Malone, 2010; Freeman \& Chapman, 2009; Kim, Paek, \& Lynn, 2010). An early study analysed the themes and content of the most viewed videos relating to the five leading cigarette brands (Elkin et al., 2010). A majority of the 163 videos had pro-tobacco content $(71 \%)$, versus a small minority containing anti-tobacco content (3\%). Most of these videos contained tobacco brand content $(71 \%)$ or the brand name in the title (71\%). A content analysis of UK Top 40 YouTube music videos showed that tobacco imagery appeared in $22 \%$ of the videos, and tobacco branding in 4\% (Cranwell et al., 2015). A recent comprehensive analysis of the 70 most popular cigarette brands on YouTube revealed over 120,000 pro-tobacco videos (Liang et al., 2015). The YouTube videos focused on the features of tobacco products (79\%), information about Web-based shops (49\%), and sales promotion (64\%).

Tobacco control researchers have also documented YouTube content related to other tobacco products popular with youth, such as hookah (Carroll, Shensa, \& Primack, 2013), cigars and cigarillos (Richardson \& Vallone, 2014), and smokeless tobacco or "dip" (Seidenberg, Rodgers, Rees, \& Connolly, 2012). The videos featuring cigars and cigarillos had been viewed almost six million times at the time of the study, were most often viewed by males, and several of the videos were most often viewed by 13-17-year-olds. Of note, the analysis of YouTube "dip" videos showed no evidence of restrictions that would block youth viewing or creating the videos.

Fewer studies have analysed the extent of tobacco promotion on other social media sites. Liang and colleagues' comprehensive study of the top 70 popular cigarette brands found that 43 of the brands had created 238 Facebook fan pages, with 1,189,976 page likes and 19,022 posts (Liang et al., 2015). An early study demonstrated that British American Tobacco (BAT) employees were promoting BAT and BAT brands 
on Facebook by joining and administrating groups, joining pages as fans and posting photographs of BAT events, products and promotional items (Freeman \& Chapman, 2010). The authors noted that, while it is not possible to determine who created those Facebook pages, according to Facebook's policies, these pages should have been created by persons authorised by BAT. Even if they did not create the pages, the fact that BAT employees joined the pages means that the company cannot deny being aware of these promotional activities.

\subsubsection{The Accessibility and Impact of Tobacco Marketing on Social Media}

Studies of youth show that self-reported exposure to tobacco content on social media is common. Data from the 2011 National Youth Tobacco Survey showed that around $50 \%$ of US middle and high-school students had received tobacco ads or promotions via Facebook or MySpace in the past 30 days (Cavazos-Rehg, Krauss, Spitznagel, Grucza, \& Bierut, 2014). Of the 32 most popular YouTube music videos containing alcohol or tobacco content, $81 \%$ of British adolsecents had seen at least one, and the average number of videos seens was 7.1 (Cranwell et al., 2015).

There is strong evidence that adolescent exposure to advertising and other tobacco media imagery in traditional media increases subsequent tobacco use (Lovato, Linn, Stead, \& Best, 2003; National Cancer Institute, 2008). Smoking depictions in mass media can shape behavior through influencing social norms, behavioural modelling, and attitudes toward smoking (Wakefield, Flay, Nichter, \& Giovino, 2003). The impact of smoking depictions in social media is likely to differ, given the fact that the content is user-generated and produced by an extended social network ostensibly connected to the viewer. The first known study to specifically assess the role of social media in maintaining or increasing tobacco behaviour among youth used a representative longitudinal panel of 200 young adults (18-24 years) (Depue, Southwell, Betzner, $\&$ Walsh, 2015). Smoking at follow-up was predicted by past 30-day exposure to social media tobacco depictions at the baseline survey, controlling for important covariates. The results suggested that social media depictions of tobacco were more important than exposure to TV and movie depictions of smoking in predicting subsequent smoking behaviour. This study did not differentiate exposure to peer-generated or brand-generated smoking depictions, so it is not known whether either of these types of content is more influential.

\section{Social Media Campaigns to Promote Healthy Behaviours}

Health promoting campaigns on social media offer unique opportunities to target youth, as social media interventions can target individuals within a certain age range. To date, however, there exists very little evidence on the effectiveness of such interventions. In the following section, we outline examples of youthfocused campaigns in this nascent area.

\subsection{Healthy Eating}

Fighting against the tide of unhealthy food and beverage marketing on social media is a herculean task when public heath budgets pale in comparison to those of international corporations. Social media platforms are also saturated with both content intended to inspire consumers to live healthier, fitter lives and advertisements promoting fad diets (Villiard \& Moreno, 2012). A quick scan of Facebook also reveals numerous celebrity-endorsed (for example https://www.facebook.com/ 12WBT) or commercial (for example https://www.face book.com/weightwatchers) weight-loss pages. A survey of 15-29-year-olds in Australia measured consumption of three types of health-related social media content on Facebook, Twitter and Instagram, and found that $31 \%$ consumed "fitspiration" (fitness inspiration) pages, $14 \%$ consumed detox pages, and $23 \%$ consumed diet/fitness plan pages (Carrotte \& Vella, 2015). Teenage girls made up almost half of all consumers of this type of content. The quality, accuracy and helpfulness of this content varies widely and has just as much potential to be harmful as beneficial to health. Clearly, young people want to access healthy lifestyle content on social media, but in order for public health institutions to break through both the competing commercial voices of the obesity-promoting and weight-loss industries, creative content and resources will be required.

It is commonplace for public health organisations and social marketing campaigns promoting healthy eating behaviours to include a social media page in their outreach and communications efforts, but there is very limited published evidence on the cost, reach, and effectiveness of these efforts. Some small-scale social marketing campaigns to promote healthy eating that incorporate social media platforms have found that people exposed to such campaigns are willing to engage on sites like Facebook and Twitter (George, Roberts, Beasley, Fox, \& Rashied-Henry, 2015; Tobey \& Manore, 2014). A small study of a Facebook and text message based weight-loss intervention aimed at US college students showed preliminary efficacy and acceptability among users (Napolitano, Hayes, Bennett, Ives, \& Foster, 2013). Conversely, a study to promote physical activity amongst students showed no differences in perceived social support or physical activity between those allocated to receive education resources only and those enrolled in a Facebook support 
group (Cavallo et al., 2012). Systematic reviews of the effect of social media on changing healthy behaviours include few studies that make use of popular social networking platforms and generally assess adult behaviours (Korda \& Itani, 2013; Williams, Hamm, Shulhan, Vandermeer, \& Hartling, 2014). While there is enthusiasm and agreement that social media holds much promise for promoting healthy eating amongst young people, this has not yet been born out in the delivery of effective programs or campaigns.

\subsection{Alcohol Harm Reduction}

It is clear that health promoters lag far behind commercial marketers in the extent and sophistication of their use of social media to communicate with young people about alcohol. Australian researchers undertook a comparative analysis of the Twitter accounts of six alcohol companies and six advocates of safe drinking and/or abstinence in May 2011 (Burton, Clark, \& Jackson, 2012; Burton, Dadich, \& Soboleva, 2013). They analysed the most recent 200 tweets for each of the accounts and found that the alcohol companies' Twitter accounts had more followers (an average of 8,210 ) than the advocates $(1,956)$; and that the alcohol company accounts were more likely to use hashtags, and to be re-tweeted. Not surprisingly, they also found in a thematic analysis that the alcohol company posts were more likely to be associated with positive stimuli. While these results should be interpreted with caution due to the differences between the two sets of accounts (such as the difficulty reported in identifying advocate accounts to follow, and the multi-national reach and large budgets of the alcohol companies), the authors' conclusion that pro-health tweeters could learn from the alcohol industry is clearly valid.

However, there are examples of the effective use of social media to bring about positive changes in alcoholrelated behaviour, such as the successful "Hello Sunday Morning" (HSM) program. HSM, established in 2009 by Australian Chris Raine, is an online program that encourages people to commit to a period of non-drinking and to blog about their experiences. HSM provides participants with a community where they can share their experiences of not drinking, reflect on the role of alcohol in their lives and the broader society, and provide one another with support to remain "dry" (Pennay, MacLean, \& Rankin, 2015). There is evidence that the nature of engagement in HSM makes this program far more than a temporary sobriety program (a limited-time challenge that people may participate in to raise funds or show support for a cause, such as FebFast and Dry July). An analysis of HSM blog posts found that participants start by posting about their goals, current drinking practices, hopes and anxieties about changing their drinking; but over the course of their involvement, move to reflecting on the role of drinking in their lives and their place in a drinking culture, and to providing advice to others commencing the journey (Carah, Meurk, \& Angus, 2015). Importantly, research has shown that HSM is not just "preaching to the converted" and engaging those predisposed to oppose excessive alcohol consumption. An analysis of data on over 3000 HSM participants found that $95 \%$ engaged in risky or highly risky drinking (Carah, Meurk, \& Hall, 2015), suggesting that the intervention has been successful in attracting those who need support to change their drinking.

\subsection{Smoking Cessation}

Tobacco control practitioners have long recognized the need to counter the prevalence of pro-smoking messages in traditional media with social marketing campaigns discouraging the uptake of smoking among young people and encouraging smokers to quit (National Cancer Institute, 2008). The use of social media platforms to deliver these types of campaigns, however, is in its infancy. Facebook is the social media site most commonly researched in regards to antismoking campaigns, with the majority of studies focusing on smoking cessation campaigns targeting young adults. Facebook, integrated into the lives of many young adults, represents a promising strategy to deliver smoking cessation interventions through the use of accessible technologies that enable user-driven participation and interaction (Ramo, Liu, \& Prochaska, 2015).

Two Canadian campaigns have utilized social media campaigns integrated with a smart-phone app to encourage smoking cessation among young adult smokers. Visitors to the Break It Off (BIO) campaign website (www.breakitoff.ca) could upload a video of their "break-up with smoking" experience as well as announce their break-up status to friends via Facebook (Baskerville, Azagba, Norman, McKeown, \& Brown, 2015). In the first four months of the campaign, total visits to the website were 44,172 , there were 3,937 installations of the app, and 339 interactions via social media components (Facebook and YouTube). The evaluation of $\mathrm{BIO}$ compared quit rates among users of the campaign materials and users of the telephone quitline of the same age (Baskerville et al., 2015); BIO users had significantly higher 7-day and 30-day quit rates compared with users of the quitline. The Crush the Crave campaign was promoted through Google and Facebook ads from April 2012 to April 2013 (Struik \& Baskerville, 2014). The campaign Facebook page had 34,690 likes and a total reach of 7,282 people. The total number of people who clicked on, liked, commented on, or shared Crush the Crave Facebook posts averaged 4000 per week. User engagement in terms of likes, comments, and shares averaged 70 per post. An analysis of the content posted to the Crush the Crave Facebook page suggested that people who commented on posts were highly engaged and that the majority of comments (77\%) showed support for 
cessation (Struik \& Baskerville, 2014).

Finally, "Picture Me Smokefree" was a pilot study using Facebook for a "photo-group" for young adult smokers and quitters (Haines-Saah, Kelly, Oliffe, \& Bottorff, 2015). Being enrolled in the study involved posting photos in a closed group in order to reflect on their smoking, their habits related to continued smoking, and the benefits of and reasons for quitting. Young adults' frequent use of mobile phones to access social networking permitted ease of access and facilitated real-time peer-to-peer support across a diverse group of participants. Nonetheless, considerable challenges with recruitment, participation, and retention were also highlighted.

\section{Implications and Future Research}

\subsection{Methodological Challenges}

It is clear that accurately measuring youth exposure to the marketing of unhealthy products on social media is a major challenge for researchers in this area. The tools available to track youth exposure to advertising in traditional broadcast media, such as Target Audience Rating Points, have not yet been adapted for digital advertising, and are not likely to be appropriate for studies measuring exposure to social media marketing. To date, studies have used data on marketing expenditure, number of Facebook pages, likes, shares, and comments as proxies for how many people are likely to be exposed, but each of these are likely to over or under-estimate actual levels of exposure. Additionally, since data on these metrics are usually aggregated, it is very difficult to ascertain the age of those exposed in this manner. The nature of online environments is such that age itself is very difficult to ascertain; for example, you are required to be aged 13 or over to have a Facebook page but there is currently no verification of the age of Facebook members.

Researchers in this field need to keep abreast of the development of tools to more accurately track exposure to social media marketing. Some studies have asked youth directly about how much marketing or promotion they are exposed to on social media, but given the nature of social media marketing (peer-topeer, user-generated content that may not be recognised as "advertising"), youth are likely to underestimate their levels of exposure. One study has used the innovative methodology of creating fictitious Instagram profiles for youth and tracking their exposure to advertising on that platform (Barry, Olunfunto, et al., 2015). This methodology could be expanded to other platforms in order to provide "case-studies" of how and when youth are exposed to unhealthy marketing.
Despite social media company policies that ban the promotion of tobacco products on their sites, and industry-based codes of conduct to restrict marketing of alcohol and unhealthy foods and beverages to youth, it is clear that youth exposure to innovative and enticing promotions for these products is common and increasing. These policies are failing to protect young people as they require constant social media monitoring; this, coupled with the explosive growth of content on social media, means such monitoring is near-impossible (Nicholls, 2012). It is evident that merely extending existing regulatory codes to include advertising on the Internet and social media is not an effective approach to reducing youth exposure to this increasing barrage of commercial messages. Further, extending existing guidelines that were developed for traditional media ignores the unique aspects and challenges of interactive digital marketing (Hastings \& Sheron, 2013; Nicholls, 2012). Most notably, advertising messages in new media are not static communications passively received by their audience, but are co-created with and amplified by consumers (Jones et al., 2015).

Protecting young people from exposure to inappropriate promotion of unhealthy products should be a priority of governments, given the substantial evidence that early and cumulative exposure is associated with increased consumption and long-term harms. Given the challenges in enforcing self-regulation regimes, there have been calls for a complete ban on social media marketing for alcohol (Hastings et al., 2010), and calls for the development of WHO FCTC guidelines for effectively restricting tobacco promotion on social media (Freeman, 2012). Finland's unprecedented ban on alcohol branded social media communications is an example of the type of regulation that can be enacted.

One of the most crucial issues to be considered when regulating advertising of harmful products in social media is whether the content is commercial in origin or is genuinely generated by consumers acting independently (Freeman, 2012). The goal of any such regulation should be to prevent commercial companies from enticing new users, not to prevent consumers from voicing their authentic opinions. The Finnish legislation prohibits the promotion of mild alcoholic drinks with campaigns in which consumers are invited to participate in games, lotteries or contests (European Centre for Monitoring Alcohol Marketing, 2014). Additionally, while citizens' personal communications are not restricted, content produced or shared by consumers-including posts, photos, video clips or ads-are no longer allowed to be used in advertising. Evaluating whether the legislation reduces the exposure of Finish youth to attractive alcohol messages will be an important avenue of future research. 
The extent of marketing on social media by commercial brands that threaten public health dwarfs that of public health agencies. This is due in part to the global scope of many of the most popular brands on social media, effectively leveraged to their advantage. These social media marketers are creating and curating fresh content on a near-daily basis that can then be adapted and broadcast across borders. Social media campaigns promoting health behaviours, on the other hand, are largely driven by local efforts that target an audience within a small jurisdiction. This narrow reach, and a tendency towards short-term campaigns, will clearly limit the ability of such campaigns to compete with global brands promoting unhealthy products with budgets in the millions of dollars.

The World Health Organization recently called for more research on the effectiveness of social media interventions for behaviour change (World Health Organization, 2011). While evidence for the impact of such campaigns is growing, much more research needs to be done on which types of social media campaigns are most likely to be effective, and for whom. Formative research should explore how social media is used by different target audiences. For example, if a campaign or intervention aims to recruit youth to an active social media group, formative research should also be conducted to determine the types of groups that youth are willing to join and remain engaged with. For some behaviours, such as smoking cessation, it appears that private groups might be more popular than open groups (Haines-Saah et al., 2015; Ramo et al., 2015).

Other questions for maximising the impact of social media campaigns relate to implementation; for example, what is the dose needed to produce the desired behaviour change, and what are the design features that encourage deeper engagement with a social media campaign? Some researchers have suggested that engagement and retention might be influenced by incentives for participation, gaming activities, or activities that emphasise socialising (Ramo et al., 2015). Others have suggested that engagement can be increased by encouraging target audiences to create their own campaign materials and post them on social media (Dooley, Jones, \& Iverson, 2012). The supportive nature of social media groups also appears to be an important factor in the appeal and success of a campaign. This can be established through the tone of moderator posts and responses, positive reinforcement, and the encouragement of sharing personal experiences.

\section{Conclusions}

The digital age offers unprecedented opportunities to reach and engage with youth, for whom social media use has become a routine daily activity. The ability to target youth, and to create content that encourages them to engage with and share campaign materials, brings a new dimension to campaigns aimed at improving the health of adolescents and young adults. At the same time, the huge advertising budgets of global commercial brands allow them to experiment with new and exciting ways to entice youth to think about, share information about, and try products which are detrimental to their health. Adequate and effective regulation of social media advertising that may have a negative impact on young people, while possible, presents many challenges. In the absence of effective regulations, it is important that young people and their parents are educated about the extent and nature of marketing on social media so that adolescents can develop into media-literate consumers.

\section{Acknowledgements}

Sandra Jones is funded by an Australian Research Council Future Fellowship (FT120100932). Becky Freeman is funded by a fellowship from the Australian National Health and Medical Research Centre.

\section{Conflicts of Interest}

The authors declare no conflict of interests.

\section{References}

ABAC Scheme. (2014). Best practice for the responsible marketing of alcohol beverages in digital marketing: Retrieved from http://www.abac.org.au/wp-content/ uploads/2014/06/ABAC-Responsible-Alcohol-Marketi ng-Code-30-4-14.pdf

Alhabash, S., McALister, A. R., Quilliam, E. T., \& Richards, J. I. (2015). Alcohol's getting a bit more social: When alcohol marketing messages on Facebook increase young adults' intentions to imbibe. Mass Communication and Society, 18(3), 350-375. doi:10.1080/ 15205436.2014.945651

Anderson, P., de Bruijn, A., Angus, K., Gordon, R., \& Hastings, G. (2009). Impact of alcohol advertising and media exposure on adolescent alcohol use: A systematic review of longitudinal studies. Alcohol and Alcoholism, 44(3), 229-243. doi:10.1093/alcalc/agn115

Australian Institute of Health and Welfare. (2014). 2013 national drug strategy household survey. Retrieved from http://aihw.gov.au/alcohol-and-other-drugs/nd shs/2013/data-and-references

Barry, A., Olunfunto, O., Martin, E., \& Jackson, Z. (2015, November 3). Alcohol industry advertising practices on social media: A case study of Instagram. Paper presented at the American Public Health Association Conference, Washington DC. Retrieved from https://apha.confex.com/apha/143am/webprogram /Paper327157.html

Barry, A. E., Johnson, E., Rabre, A., Darville, G., Donovan, K. M., \& Efunbumi, O. (2015). Underage access to 
online alcohol marketing content: a YouTube case study. Alcohol and Alcoholism, 50(1), 89-94. doi:10. 1093/alcalc/agu078

Baskerville, N. B., Azagba, S., Norman, C., McKeown, K., \& Brown, K. S. (2015). Effect of a digital social media campaign on young adult smoking cessation. Nicotine \& Tobacco Research. doi:10.1093/ntr/ntv119

Beese, J. (2015, March 30). Please link responsibly: Social media guidelines for alcohol marketing. Sprout Social. Retrieved from http://sproutsocial.com/ insights/social-media-alcohol-marketing

Bernat, D. H., Klein, E. G., \& Forster, J. L. (2012). Smoking initiation during young adulthood: A longitudinal study of a population-based cohort. Journal of Adolescent Health, 51(5), 497-502. doi:10.1016/j.jado health.2012.02.017

Boelsen-Robinson, T., Backholer, K., \& Peeters, A. (2015) Digital marketing of unhealthy foods to Australian children and adolescents. Health Promotion International. doi:10.1093/heapro/dav008

Burton, S., Clark, L., \& Jackson, K. (2012). The association between seeing retail displays of tobacco and tobacco smoking and purchase: Findings from a diary-style survey. Addiction, 107(1), 169-175. doi:10.1111/j.13 60-0443.2011.03584.x

Burton, S., Dadich, A., \& Soboleva, S. (2013). Competing voices: Marketing and counter-marketing alcohol on Twitter. Journal of Nonprofit \& Public Sector Marketing, 25(2), 186-209. doi:10.1080/10495142.2013.787 836

Cairns, G., Angus, K., \& Hastings, G. (2009). The extent, nature and effects of food promotion to children: $A$ review of the evidence to December 2008. World Health Organization.

Carah, N., Meurk, C., \& Angus, D. (2015). Online selfexpression and experimentation as 'reflectivism': Using text analytics to examine the participatory forum Hello Sunday Morning. Health: An Interdisciplinary Journal for the Social Study of Health, Illness and Medicine, 1-17. doi:10.1177/1363459315596799

Carah, N., Meurk, C., \& Hall, W. (2015). Profiling Hello Sunday Morning: Who are the participants? International Journal of Drug Policy, 26(2), 214-216. doi:10.1016/j.drugpo.2014.07.019

Carroll, M. V., Shensa, A., \& Primack, B. A. (2013). A comparison of cigarette-and hookah-related videos on YouTube. Tobacco Control, 22(5), 319-323. doi:10. 1136/tobaccocontrol-2011-050253

Carrotte, E. R., \& Vella, A. M. (2015). Predictors of "liking" three types of health and fitness-related content on social media: A cross-sectional study. Journal of Medical Internet Research, 17(8). doi:10. 2196/jmir.4803

Casswell, S. (2012). Current status of alcohol marketing policy-An urgent challenge for global governance. Addiction, 107(3), 478-485. doi:10.1111/j.1360-0443. 2011.03701.x
Cavallo, D. N., Tate, D. F., Ries, A. V., Brown, J. D., DeVellis, R. F., \& Ammerman, A. S. (2012). A Social mediabased physical activity intervention: A randomized controlled trial. American Journal of Preventive Medicine, 43(5), 527-532. doi:http://dx.doi.org/10.1016/ j.amepre.2012.07.019

Cavazos-Rehg, P. A., Krauss, M. J., Sowles, S. J., \& Bierut, L. J. (2015). "Hey everyone, I'm drunk." An evaluation of drinking-related Twitter chatter. Journal of Studies on Alcohol and Drugs, 76(4), 635-643. doi:10.15288/jsad.2015.76.63

Cavazos-Rehg, P. A., Krauss, M. J., Spitznagel, E. L., Grucza, R. A., \& Bierut, L. J. (2014). Hazards of new media: Youth's exposure to tobacco ads/promotions. Nicotine \& Tobacco Research, 16(4), 437-444. doi:10.1093/ntr/ntt168

Centers for Disease Control and Prevention (CDC). (2015). Current cigarette smoking among adultsUnited States, 2005-2014. Morbidity and Mortality Weekly Report, 64(44), 1233-1240.

Colenso BBDO. (2015, November 11). Motel Burger King. Facebook Awards 2015. Retrieved from https:// www.facebook-studio.com/gallery/submission/mote I-burger-king-3

Cranwell, J., Murray, R., Lewis, S., Leonardi-Bee, J., Dockrell, M., \& Britton, J. (2015). Adolescents' exposure to tobacco and alcohol content in YouTube music videos. Addiction, 110(4), 703-711. doi:10.1111/ add. 12835

Depue, J. B., Southwell, B. G., Betzner, A. E., \& Walsh, B. M. (2015). Encoded exposure to tobacco use in social media predicts subsequent smoking behavior. American Journal of Health Promotion, 29(4), 259-261. doi:10.4278/ajhp.130214-ARB-69

DMR. (2015, November 11). By the numbers: $150+$ intersting Instagram statistics. DMR. Retrieved from http://expandedramblings.com/index.php/importan t-instagram-stats $/ 2$

Dooley, J. A., Jones, S., \& Iverson, D. (2012). Web 2.0: An assessment of social marketing principles. Journal of Social Marketing, 2(3), 207-221.

Duggan, M., Ellison, N. B., Lampe, C., Lenhart, A., \& Madden, M. (2015). Social media update 2014. Washington: Pew Research Center.

Elkin, L., Thomson, G., \& Wilson, N. (2010). Connecting world youth with tobacco brands: YouTube and the internet policy vacuum on Web 2.0. Tobacco Control, 19(5), 361-366. doi:10.1136/tc.2010.035949

European Centre for Monitoring Alcohol Marketing. (2014). Finland bans alcohol branded social media communication in 2015. Retrieved from http:// eucam.info/2014/02/27/finland-bans-alcohol-brand ed-social-media-communication-in-2015

Facebook. (2014). Facebook reports fourth quarter and full year 2013 results [Press release].

Facebook. (2015a). Facebook advertising policies. Facebook. Retrieved from https://www.facebook. 
com/policies/ads

Facebook. (2015b). Facebook pages terms. Facebook. Retrieved from https://www.facebook.com/page_ guidelines.php

Forsyth, S. R., \& Malone, R. E. (2010). "I'Il be your cigarette-Light me up and get on with it": Examining smoking imagery on YouTube. Nicotine \& Tobacco Research, 12(8), 810-816. doi:10.1093/ntr/ntq101

Freeman, B. (2012). New media and tobacco control. Tobacco Control, 21(2), 139-144. doi:10.1136/ tobaccocontrol-2011-050193

Freeman, B., \& Chapman, S. (2009). Open source marketing: Camel cigarette brand marketing in the "Web 2.0" world. Tobacco Control, 18(3), 212-217. doi:10.1136/tc.2008.027375

Freeman, B., \& Chapman, S. (2010). British American tobacco on Facebook: Undermining Article 13 of the global World Health Organization framework convention on tobacco control. Tobacco Control. doi:10.1136/tc.2009.032847.

Freeman, B., Kelly, B., Baur, L., Chapman, K., Chapman, S., Gill, T., \& King, L. (2014). Digital junk: Food and beverage marketing on Facebook. American Journal of Public Health, 104(12), 56-64. doi:10.2105/ajph. 2014.302167

Freeman, B., Kelly, B., Vandevijvere, S., \& Baur, L. (2015). Young adults: Beloved by food and drink marketers and forgotten by public health? Health Promotion International. doi:10.1093/heapro/dav081

George, K. S., Roberts, C. B., Beasley, S., Fox, M., \& Rashied-Henry, K. (2015). Our health is in our hands: A social marketing campaign to combat obesity and diabetes. American Journal of Health Promotion. doi:10.4278/ajhp.130625-ARB-323

Google. (2015). Advertising policies help. Google. Retrieved from https://support.google.com/adwords policy/answer/6014299?hl=en\&ref_topic $=1626336$

Haines-Saah, R. J., Kelly, M. T., Oliffe, J. L., \& Bottorff, J. L. (2015). Picture me smokefree: A qualitative study using social media and digital photography to engage young adults in tobacco reduction and cessation. Journal of Medical Internet Research, 17(1), e27. doi:10.2196/jmir.4061

Harris, J. L., Schwartz, M. B., Munsell, C. R., Dembek, C., Liu, S., LoDolce, M., . . . Kidd, B. (2013). Fast food FACTS 2013: Measuring progress in nutrition and marketing to children and teens. Hartford: Yale Rudd Center for Food Policy \& Obesity. Retrieved from http://www.fastfoodmarketing.org/media/FastFood FACTS_report.pdf

Hastings, G., Brooks, O., Stead, M., Angus, K., Anker, T., \& Farrell, T. (2010). Failure of self regulation of UK alcohol advertising. British Medical Journal, 340, b5650. doi:10.1136/bmj.b5650

Hastings, G., \& Sheron, N. (2013). Alcohol marketing: grooming the next generation: Children are more exposed than adults and need much stronger protec- tion. British Medical Journal, 346, f1227. doi:10.1136/bmj.f1227

Hebden, R., Lyons, A. C., Goodwin, I., \& McCreanor, T. (2015). "When you add alcohol, it gets that much better": University students, alcohol consumption, and online drinking cultures. Journal of Drug Issues. doi:10.1177/0022042615575375

Hoffman, E. W., Pinkleton, B. E., Austin, E. W., \& ReyesVelazquez, W. (2014). Exploring college students' use of general and alcohol-related social media and their associations with alcohol-related behaviors. Journal of American College Health, 62(5), 328-335. doi:10.1080/07448481.2014.902837

Jernigan, D. H., \& Rushman, A. E. (2014). Measuring youth exposure to alcohol marketing on social networking sites: Challenges and prospects. Journal of Public Health Policy, 35(1), 91-104. doi:10.1057/jphp. 2013.45

Jones, S. C., \& Gordon, R. (2013). Regulation of alcohol advertising: Policy options for Australia. Evidence Base, 2. Retrieved from http://journal.anzsog.edu. au/publications/12/EvidenceBase2013Issue2012.pdf

Jones, S. C., Hall, D., \& Munro, G. (2008). How effective is the revised regulatory code for alcohol advertising in Australia? Drug and Alcohol Review, 27(1), 29-38. doi:10.1080/09595230701499175

Jones, S. C., Robinson, L., Barrie, L., Francis, K., \& Lee, J. K. (2015). Association between young Australian's drinking behaviours and their interactions with alcohol brands on Facebook: Results of an online survey. Alcohol and Alcoholism. doi:10.1093/alcalc/agv113

Jones, S. C., Robinson, R., \& Barrie, L. (2013). Alcohol marketing and branding in social media (Vol. 1). Victoria: Cancer Council Victoria.

Kim, K., Paek, H. J., \& Lynn, J. (2010). A content analysis of smoking fetish videos on YouTube: Regulatory implications for tobacco control. Health Communication, 25(2), 97-106. doi:10.1080/104102 30903544415

Korda, H., \& Itani, Z. (2013). Harnessing social media for health promotion and behavior change. Health Promotion Practice, 14(1), 15-23. doi:10.1177/15248 39911405850

Lenhart, A. (2015, April 9). Teens, social media \& technology overview 2015. Pew Research Center. Retrieved from: http://www.webcitation.org/6fOcNH yBI

Liang, Y., Zheng, X., Zeng, D. D., Zhou, X., Leischow, S. J., \& Chung, W. (2015). Exploring how the tobacco industry presents and promotes itself in social media. Journal of Medical Internet Research, 17(1). doi:10.2196/jmir.3665

Litt, D. M., \& Stock, M. L. (2011). Adolescent alcoholrelated risk cognitions: The roles of social norms and social networking sites. Psychology of Addictive Behaviors, 25(4), 708-713.

Lovato, C., Linn, G., Stead, L. F., \& Best, A. (2003). Impact 
of tobacco advertising and promotion on increasing adolescent smoking behaviors. Cochrane Database of Systematic Reviews. doi:10.1002/14651858.CD00 3439

Mart, S., Mergendoller, J., \& Simon, M. (2009). Alcohol promotion on Facebook. Journal of Global Drug Policy and Practice, 3(3).

Montgomery, K. C., Chester, J., Grier, S. A., \& Dorfman, L. (2012). The new threat of digital marketing. Pediatric Clinics of North America, 59(3), 659-675. doi:10. 1016/j.pcl.2012.03.022

Moreno, M. A., Christakis, D. A., Egan, K. G., Brockman, L. N., \& Becker, T. (2012). Associations between displayed alcohol references on Facebook and problem drinking among college students. Archives of Pediatrics and Adolescent Medicine, 166(2), 157-163. doi:10.1001/archpediatrics.2011.180

Napolitano, M. A., Hayes, S., Bennett, G. G., Ives, A. K., \& Foster, G. D. (2013). Using facebook and text messaging to deliver a weight loss program to college students. Obesity, 21(1), 25-31. doi:10.1002/oby.202 32

National Cancer Institute. (2008). The role of the media in promoting and reducing tobacco use. Tobacco Control Monograph, No. 19. Bethesda, MD: U.S. Department of Health and Human Services.

Nicholls, J. (2012). Everyday, everywhere: Alcohol marketing and social media-Current trends. Alcohol and Alcoholism, 47(4), 486-493. doi:10.1093/alcalc/ags043

Obesity Policy Coalition. (2011). Food advertising regulation in Australia. Policy brief. Retrieved from http://www.opc.org.au/downloads/positionpapers/ policy-brief-food-advertising-regulation-australia.pdf

Ofcom. (2014). Children and parents: Media use and atttidues report. Retrieved from http://stakeholders. ofcom.org.uk/market-data-research/other/researchpublications/childrens/children-parents-oct-14

Ogden, C. L., Carroll, M. D., Kit, B. K., \& Flegal, K. M. (2014). Prevalence of childhood and adult obesity in the United States, 2011-2012. JAMA Internal Medicine, 311(8), 806-814. doi:10.1001/jama.2014. 732

Our Social Times. (2013, June 3). 5 outstanding Facebook marketing case studies. Oreo's daily twist. Our Social Times. Retrieved from http://oursocialtimes.com/5outstanding-facebook-marketing-case-studies

Pennay, A., MacLean, S., \& Rankin, G. (2015). Hello Sunday Morning: Alcohol, (non)consumption and selfhood. International Journal of Drug Policy, 28, 67-75. doi: http://dx.doi.org/10.1016/j.drugpo.2015.10.008

Pew Research Center. (2014). Political polarization and media habits. Retrieved from http://www.journal ism.org/files/2014/10/Political-Polarization-and-Med ia-Habits-FINAL-REPORT-7-27-15.pdf

Pew Research Center. (2015). Teen, social media and technology overview 2015. Retrieved from http:// www.pewinternet.org/2015/04/09/teens-social-med ia-technology-2015

Powell, L. M., Harris, J. L., \& Fox, T. (2013). Food marketing expenditures aimed at youth putting the numbers in context. American Journal of Preventive Medicine, 45(4), 453-461. doi:10.1016/j.amepre.20 13.06.003

Ramezani, K. A., Terdal, F., Pepper, N., \& Anderson, K. G. (2014). Twitter: A window on alcohol use? Drug and Alcohol Dependence, 140, e182. doi:http://dx.doi. org/10.1016/j.drugalcdep.2014.02.510

Ramo, D. E., Liu, H., \& Prochaska, J. J. (2015). A mixedmethods study of young adults' receptivity to using Facebook for smoking cessation: If you build it, will they come? American Journal of Health Promotion, 29(4), 126-135. doi:10.4278/ajhp.130326-QUAL-128

Richardson, A., \& Vallone, D. M. (2014). YouTube: A promotional vehicle for little cigars and cigarillos? Tobacco Control, 23(1), 21-26. doi:10.1136/tobacco control-2012-050562

Ridout, B., Campbell, A., \& Ellis, L. (2011). 'Off your Face(book)': Alcohol in online social identity construction and its relation to problem drinking in university students. Drug and Alcohol Review, 31(1), 20-26.

Ross, M. (2014). Facebook turns 10: The world's largest social network in numbers. $A B C$ News Online. Retrieved from http://www.abc.net.au/news/201402-04/facebook-turns-10:-the-social-network-innumbers $/ 5237128$

SAMHSA. (2013). Table 2.46B-Alcohol use, binge alcohol use, and heavy alcohol use in the past month among persons aged 18 or older, by demographic characteristics: Percentages, 2012 and 2013. National Survey on Drug Use and Health. Retrieved from: http://www.samhsa.gov/data/sites/default/ files/NSDUH-DetTabsPDFWHTML2013/Web/HTML/ NSDUH-DetTabsSect2peTabs43to84-2013.htm\#tab2. $46 \mathrm{~b}$

Seidenberg, A. B., Rodgers, E. J., Rees, V. W., \& Connolly, G. N. (2012). Youth access, creation, and content of smokeless tobacco ("dip") videos in social media. Journal of Adolescent Health, 50(4), 334-338. doi:10.1016/j.jadohealth.2011.09.003

Shively, K. (2014, May 22). Lessons from Coca-Cola's social media strategy: Cohesive campaigns and creative content. The Simply Measured Blog. Retrieved from http://simplymeasured.com/blog/lessons-from-cocacolas-social-media-strategy-cohesive-campaigns-andcreative-content/\#i.1ocilc1ciie9zw

Smith, K. C., Cukier, S., \& Jernigan, D. H. (2014). Regulating alcohol advertising: Content analysis of the adequacy of federal and self-regulation of magazine advertisements, 2008-2010. American Journal of Public Health, 104(10), 1901-1911. doi:10.2105/AJPH.2013. 301483

Smith, L. A., \& Foxcroft, D. R. (2009). The effect of alcohol advertising, marketing and portrayal on drinking 
behaviour in young people: Systematic review of prospective cohort studies. BMC Public Health, 9. doi:10.1186/1471-2458-9-51

Socintel360. (2014, April 4). Food \& Beverage brands to add $\$ 775$ million to social media advertising budgets in 2014 in response to increased social media mobile usage and rising consumer incomes. Socintel360. Retrieved from http://www.socintel360.com/foodamp-beverage-brands-to-add-775-million-to-socialmedia-advertising-budgets-in-2014-in-response-toincreased-social-media-mobile-usage-and-risingconsumer-incomes/63/

Struik, L. L., \& Baskerville, N. B. (2014). The role of Facebook in Crush the Crave, a mobile and social mediabased smoking cessation intervention: Qualitative framework analysis of posts. Journal of Medical Internet Research, 16(7), e170. doi:10.2196/jmir.3189

Tobey, L. N., \& Manore, M. M. (2014). Social media and nutrition education: The food hero experience. Journal of Nutrition Education and Behavior, 46(2), 128-133. doi:10.1016/j.jneb.2013.09.013

Villiard, H., \& Moreno, M. A. (2012). Fitness on facebook: Advertisements generated in response to profile content. Cyberpsychology, Behavior, and Social Networking, 15(10), 564-568. doi:10.1089/cyber.20 11.0642

Wakefield, M., Flay, B., Nichter, M., \& Giovino, G. A. (2003). Role of the media in influencing trajectories of youth smoking. Addiction, 98, 79-103.

West, J. H., Hall, P. C., Prier, K., Hanson, C., L., GiraudCarrier, C., Neeley, E. S., \& Barnes, M. D. (2012). Temporal variability of problem drinking on Twitter. Open Journal of Preventive Medicine, 2(1), 43-48. doi:10.4236/ojpm.2012.21007
WHO Framework Convention on Tobacco Control. (2015). Parties to the WHO framework convention on tobacco control. Retrieved from http://www.who. int/fctc/signatories_parties/en/index.html

Williams, G., Hamm, M. P., Shulhan, J., Vandermeer, B., \& Hartling, L. (2014). Social media interventions for diet and exercise behaviours: A systematic review and meta-analysis of randomised controlled trials. British Medical Journal Open, 4(2). doi:10.1136/bmj open-2013-003926

Williams, S. (2013). Action needed to combat food and drink companies' social media marketing to adolescents. Perspect Public Health, 133(3), 146-147. doi:10.1177/1757913913484871

Winpenny, E. M., Marteau, T. M., \& Nolte, E. (2014). Exposure of children and adolescents to alcohol marketing on social media websites. Alcohol and Alcoholism, 49(2), 154-159. doi:10.1093/alcalc/agt174

World Health Organization. (2010). Set of recommendations on the marketing of foods and non-alcoholic beverages to children. Retrieved from http:// whqlibdoc.who.int/publications/2010/97892415002 10_eng.pdf

World Health Organization. (2011). mHealth: New horizons for health through mobile technologies. Global observatory for eHealth series (Vol. 3). Geneva: World Health Organization.

YouTube. (2015). Statistics. YouTube. Retrieved from http://www.youtube.com/yt/press/statistics.html

YPulse. (2015). \#FoodPorn: The growing influence of social food. YPulse. Retrieved from www.ypulse. com/post/view/foodporn-the-growing-influence-ofsocial-food

\section{About the Authors}

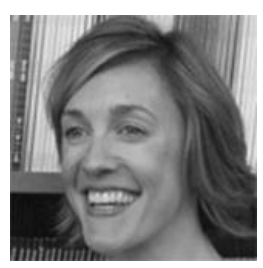

\section{Dr. Sally Dunlop}

Sally Dunlop is a Senior Research Officer in the Division of Cancer Screening and Prevention at the Cancer Institute New South Wales and an adjunct Research Fellow in the School of Public Health at the University of Sydney. As a behavioural scientist, her research focuses on identifying factors that influence behaviour change. Her current research focuses primarily on the impact of anti-smoking media campaigns, tobacco promotion, and tobacco control policies on smoking-related outcomes.

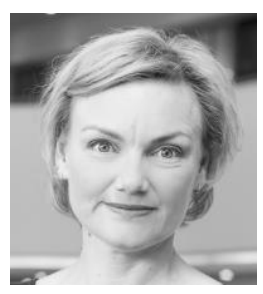

\section{Dr. Becky Freeman}

Becky Freeman is an Early Career Research Fellow and Senior Lecturer at the School of Public Health, University of Sydney. Her primary research interests include tobacco control, obesity prevention, and how online and social media influence public health. She is an established authority on the potential of the Internet to circumvent tobacco advertising bans and has pioneered research in tracking and analysing online social media content. 


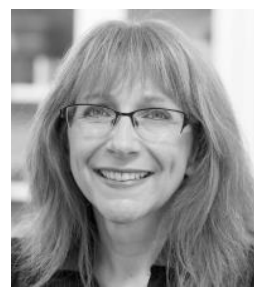

\section{Dr. Sandra C. Jones}

Professor Sandra Jones is an ARC Future Fellow and Director of the Centre for Health and Social Research (CHaSR) at the Australian Catholic University in Melbourne. Sandra's research focuses on the relationship between media and health, including the impacts of advertising in the print and electronic media on health behaviour, and the use of social marketing to improve population health. For more than a decade Sandra has been researching influences on young people's alcohol consumption, including alcohol advertising and marketing. 